\title{
Conclusion: Learning the Lessons from West African Experiences of Security Sector Governance
}

\author{
Alan Bryden ${ }^{\star}$ and Fairlie Chappuis ${ }^{\dagger}$ \\ *Assistant Director and Head of Public-Private Partnerships Division at the \\ Geneva Centre for the Democratic Control of Armed Forces (DCAF) \\ †Programme Manager within the Research Division at the Geneva Centre for \\ the Democratic Control of Armed Forces (DCAF)
}

\section{Introduction}

Security sector reform (SSR) in Africa has been accompanied by both a strong critiqueandan uncomfortablereality. The critique characterizesinternationallysupported SSR as externally generated and driven, dislocated from African realities and needs (Donais, Halden and Egnell). The uncomfortable reality is that an agenda to promote greater oversight and accountability of the security sector is not and has not been attractive to many African political and security elites (Bryden and Olonisakin 9-10). Arguably, exogenous and endogenous concerns over SSR in Africa are two sides of the same coin; they reflect the costs of approaches that pay only lip service to democratic security sector governance. While legitimate critiques need to be taken seriously, there is a risk of doing more harm than good if the central insight that underpins the SSR discourse is obscured: good governance of the security sector is a key enabler for wider progress. Indeed, the key message emerging from this volume is that a failure to understand, acknowledge and address dysfunctional security sector governance not only undermines SSR (whether labeled as such or not) but generates wider, negative impacts on prospects for security, development and democracy.

How to cite this book chapter:

Bryden, A and Chappuis, F. 2015. Conclusion: Learning the Lessons from West African

Experiences of Security Sector Governance. In: Bryden, A and Chappuis, F (eds.)

Learning from West African Experiences in Security Sector Governance, Pp. 139-156. London: Ubiquity Press. DOI: http://dx.doi.org/10.5334/bau.h. License: CC-BY 4.0. 
In each of the six narratives collected in this volume, national experts examine the micro-dynamics behind specific moments that make up larger reform processes, shedding light on the enabling or constraining factors that shape specific efforts to alter the landscape of security sector governance. The accounts provided by the authors represent a balancing act between contextual layering and detailed process analysis. Both elements are important. An appreciation of historical and political framing conditions is essential to understanding opportunities and constraints on reform. At the same time, the focus on specific reform moments and key actors generates practical lessons through considering reform processes from the inside out.

This concluding chapter considers the lessons that can be drawn from these selected African experiences in security sector governance. It begins by offering an analysis based on a comparative reading of the six narratives, seeking to identify typical structural conditions and patterns that have conditioned reform efforts. Drawing on this analysis, a number of key lessons for the promotion of democratic security sector governance are identified, including specific implications for international support to SSR. Finally, potential opportunities are considered for national actors to lead governance-focused reform processes in West Africa.

\section{Unpacking the micro-dynamics of security sector governance}

The six examples of reform recounted in this volume are not directly comparable in the sense of conventional comparative analysis. They focus on different historical periods and vary in scope from broader perspectives on national SSR processes over a given period (Guinea, Mali and Senegal) to more specific analyses of change processes in security sector institutions and what this tells us about wider security sector governance dynamics (Ghana, Liberia, Nigeria).

Beyond the structural differences that tend to distinguish Anglophone and Francophone governance structures, ${ }^{1}$ each context has experienced its own distinct trajectory of social, economic and political development. Today, Ghana, Nigeria and Senegal are regional power houses while Guinea, Liberia and Mali deal with the consequences of recent conflict and political upheaval. This diversity masks the similarities these narratives share and it is only in looking through the lens of iterative and gradual governance reform that these commonalities become clear. In particular, reform in all these accounts took place in the context of legacies of security governance that had established security as a reserved domain for elite political and security actors and perpetuated adversarial relations between security services and the executive; between the executive and other branches of government, including the opposition; and between government and the wider public, and their representatives in civil society. Thus, despite the variety of political and institutional configurations across the six examples, all share similar problems: an 
institutional landscape of reserved domains in the security services, strong executives, weak legislatures, co-opted judiciaries, and confrontational relationships between the state and civil society. This section explores the implications of these pathologies of dysfunctional security sector governance from the perspective of reform as an iterative and gradual process.

\section{Security as a reserved domain}

Across the variety of national experiences evoked in these six chapters, treatment of security affairs has traditionally been restricted to the highest ranks of the security services and elite civilian governance actors. Since this trait is most directly associated with autocratic or dictatorial rule, it is all the more remarkable to find that the tendency to reserve security for elite control figures so prominently whether in the transition context of Guinea, democratizing contexts of Nigeria or post-war Liberia, the consolidating democracies of Ghana or Mali, and even the established democracy of Senegal. Reserved domains had three distinct effects on the wider security sector governance environment: first, the political class beyond the presidential circle found little interest in discussing, or attempting to influence security decision-making; second, it created a wall between the security services and popular concerns over security; and third, it generated a climate of suspicion among security 'insiders' over any role for perceived domestic 'outsiders' in security sector governance. These deeply entrenched attitudes created barriers to change because privileged elites failed to recognize the need for or possible benefits of reform, while potential reform constituencies were disenfranchised through the absence of entry points for engagement.

In terms of the structural conditions of security sector governance, the immediate implication was that the margin for action in favour of reform was highly restricted in each case. This demonstrates that if security institutions principally serve the interests of regime security, little political space will be ceded for other stakeholders to fulfil legitimate roles and responsibilities regardless of their constitutional or otherwise formal authority to do so. In these circumstances, the security sector is not responsive to public security needs, nor inclusive of representative voices from across the population, and fails to win trust and legitimacy through practices of participation or transparency. Thus in Mali, Moulaye tellingly points out that no public documents on security were issued prior to 2009. Even in Senegal, with a history of republican armed and security forces, defence secrecy is a common argument deployed to stop discussion of security matters in its tracks. This culture of secrecy, deeply entrenched in all the contexts, can be linked to the tradition of treating security as a sovereign imperative, by the state and for the state, instead of a matter of public service provision in the interests of the population. Institutionally, this 
tendency frequently expresses itself in the dominance of the President's office in security affairs, and the exclusion of oversight actors and institutions regardless of their formal roles and responsibilities.

Across all six narratives a common theme resulting from the dynamic of reserved domains was the fact that political and security elites failed to recognise the roles, responsibilities and rights of other stakeholders in security sector governance. By the same token, public governance actors displayed little sense of their own relevance in ensuring effective management and oversight of the security sector. Weak parliamentary and judicial branches thus failed to provide a counterbalance to the executive. On the one hand, informal influences prevented the exercise of authority as it was formally distributed: the real power brokers were not necessarily those assigned power by the 'rules on paper' that defined the formal arrangements of security sector governance. On the other hand, it is also relevant that populations as well as security and political elites themselves had no experience of any other type of political culture on which to imagine a different way of doing things. This lack of an alternative vision for security helps to explain how opportunities for change could be neglected, overlooked or easily missed even when structural conditions might allow the exercise of formal authority in favour of better security sector governance.

Complex power dynamics shape the relationships between political and security elites. Regime security imperatives lead to inter-and intra-institutional distortions in the security sector. This is a result of executive authorities seeking to protect themselves through balancing different actors and interests. As examples of the former, in Ghana the police was reinforced as a counter-balance to the military whereas in Guinea the police was subordinate to and under-resourced in comparison with the military. Intra-institutional meddling by the executive in the form of promotions and preferment along ethnic or regional lines in order to preserve authority figures at different times in all of these national narratives except Senegal. Yet in this jockeying for position, opportunities for reform could also be created when occasionally an imbalance of power or a moment of shift softened structural constraints on reform. At such moments, reform-minded individuals could exercise influence in favour of better governance. If not resulting in an instant transformation, such small steps held at least the potential to become significant in a chain of events that might lead ultimately to substantive improvements. For example, in Liberia, apparently modest efforts by new parliamentarians to exercise their powers of oversight and control in the face of a traditionally dominant executive over time helped to create a new precedent in executive-legislative relations over security matters. This shift was marked by many small firsts, each of which alone might appear insignificant but which developed into a pattern of improved security sector governance: for the first time security officials were summoned to account before the responsible legislative committees; for the first time the bill for a major new piece of the national security 
architecture was put to public hearing before being signed into law; for the first time civil society input on the legislative draft was sought; for the first time legislators sought access to and input on the executive's plans for defence reform. Whether or not these moments of potential change become missed opportunities or small evolutions depends at once on the individuals involved and the specific configuration of the power balance which they sought to change, again emphasizing the importance of understanding the micro-dynamics of security sector governance.

Civil-military relations characterized by exclusion and mistrust create incentives for powerful actors to stall reform agendas. As Moulaye demonstrates, in Mali, these dynamics permitted security sector elites undue influence on policy decisions, demonstrated by the fact that vested interests in the defence services were able to stall and eventually halt completely the defence reform process in 2005. While in principle the executive held all the cards in determining security policy (and the shape of SSR), in practice the security sector could exercise an indirect veto on reform agendas. Yet at the same time, as evident in the narratives where change was brought about by reform-minded security officials in the context of pacted military transitions, this indirect veto could also be turned to the purposes of reform. Bangoura describes how General Konaté in Guinea could guide the transition because he was able to use his vested interests in the defence sector to push the institution towards a withdrawal from politics. Similarly, in Nigeria, Obasanjo as both a military insider but also an elected president made use of his vested interests as a resource for reform.

If it is evident that the nature of reserved domains means that individuals within the security and political elite wield undue influence sometimes in favour of reform but most often in their own interest, then another manifestation of this dynamic is that security sector reform can become captive to other, unrelated political agendas. Under the Obasanjo administration in Nigeria, momentum for reform of the military was lost when the President tried to overturn the constitution by seeking a $3^{\text {rd }}$ term in office. The resulting tensions between the executive and legislative meant that pressure for military reform waned and many hard-fought gains were lost when the wrangling over the presidential terms stymied efforts to enact relevant new legislation and constitutional amendments. As Aiyede notes, subsequent heads of state confined their role to controlling the appointment of senior positions until Boko Haram forced SSR back onto the national agenda. A similar dynamic was perhaps narrowly avoided in the transition from single to multi-party democracy in Senegal, when Wade's desire to remain in office threatened unprecedented instability. If ultimately this fate was avoided with the peaceful transition to new leadership under Macky Sall, this only reinforces the point that where security is treated as a reserved domain it is captive to the vagaries of political competition, which can work both against and in favour of better security sector governance. 


\section{Executive dominance in security matters}

A further commonality among each of the narratives is that support for reform at the level of the executive has been a determining factor (or at least disproportionately important) in how far and how fast reforms progressed in practice. Examples where progress was made quickly over a short period were characterized by strong leadership from reform champions who either enjoyed delegated authority from the head of state or were able to fill a power vacuum resulting from transition to advance their agenda. This was the case with Guinea, under the leadership of the transitional government; in Senegal, when the new president threw his political weight behind policy development; and in Mali, when the responsible minister moved quickly to allay criticisms of police behaviour by initiating reforms. The influence of support at the executive level showed that change could come suddenly and reach surprisingly far where the full weight of a dominant executive was bent on achieving change.

Naturally the inverse is also true: thus the importance of top level political will is confirmed by the fact that reform processes stalled or suffered reversals when executive support was withdrawn. If it may seem obvious that SSR is unlikely to succeed where the executive is not prepared to stake its political capital, it should be noted that subtleties of resistance emerged, taking the form of more nuanced forms than the straight-forward rejection of the SSR agenda. Tactics for back-tracking on commitments included linking reform in one area to reform in another, effectively making the whole process hostage to particular interests (as the analysis of stalled defence reform in Mali shows); declining to translate pronouncements and political commitments in favour of SSR into concrete reform projects (as in Senegal since 2013); or implementing a strategic slow-down in reform such that progress is held back to the point of stalling altogether (for example, in Guinea in the face of a volatile political environment after the 2010 transition was completed).

A qualitatively different but no less real problem of executive dominance lies in the reliance on key individuals. Thus, the commitment of President Sirleaf to the Liberian reform process needs to be backed up by the establishment of strong institutions that can sustain this process beyond her term in office. Even in Liberia, where unprecedented efforts have been made to reinforce institutions, the culture of strong presidential rule can be found in the extra-budgetary authority utilised by the President and the reticence to give up the practice of presidential appointments which extends networks of patronage deep into the operative levels of security sector management. The influence of strong reformist figures is also evident in the examples of Kofi Abrefa Busia in Ghana whose leadership and advocacy was the determining factor behind the creation of meaningful control and oversight of the police through the initial establishment of the Police Council. Similarly during his early terms in office, Obasanjo proved that extensive changes could be made quickly in Nigeria. Yet in 
both Ghana and Nigeria the problem of the reliance on key individuals is aptly demonstrated. In both cases, once these key actors were removed from political office (Busia) or withdrew their support (Obasanjo), reform momentum faltered immediately.

The withdrawal of executive support may also reflect a failure to appreciate the gravity of what is at stake. In Mali during the period under study, it is possible that executive authorities simply did not fully appreciate the danger to which an unaccountable and ineffective security sector left the state exposed. This demonstrates that if reform is least challenging during periods of stability and peace, it also less pressing. Building momentum for reform in the face of a hypothetical threat is more difficult than when presented with a clear and present danger to the security of the state. Clearly articulating the threat to national security posed by dysfunctional security sector governance could thus offer opportunities to reinforce political will: events in Mali since 2012, and in northern Nigeria since the resurgence of Boko Haram, amply illustrate the dangers that exist and in both countries have led to renewed calls for security sector reform.

\section{Inadequate security sector oversight and accountability}

Each of the narratives presented in this volume emphasize the limited space available for democratic oversight of the security sector. It is also clear that there is little or no culture of challenging the pre-eminent role played by political and security elites. It is therefore essential to manage expectations around change processes. As Sayndee points out, efforts to promote democratic security sector governance in Liberia over the past decade need to be set against a culture of regime-focused security that stretches back to the origins of the Liberian state. If this trend goes back longer in Liberia than elsewhere in the region, the same could still be said for the other states addressed in this volume.

Weak parliaments failed to offer an effective counter-balance to the influence of the executive. In Guinea and Mali, the parliament is characterised as a "rubber stamp" institution, offering unconditional and uncritical support to executive initiatives, failing to perform its oversight function, and not making use of legal authority to review, amend and initiate legislation. Without a credible parliament, reforms are vulnerable to retrenchment in the event of a change in political leadership. For this reason, according to Cissé, in Senegal despite some improvements in parliamentary capacity, a parliament that is inexperienced in security matters is still considered vulnerable to executive influence. Yet at the same time, the inverse is also true: Liberia's experience demonstrates that a parliament that can improve its performance even in a piecemeal fashion can nevertheless make substantive contributions to improving security sector governance. 
Civil society has been the strongest and most vocal advocate for security sector reforms. The essential operative role played by civil society in giving voice to and channelling public discontent underlines their importance as change agents in reform processes. Beyond the pressure generated through advocacy, a significant role has been played by civil society in injecting new thinking into security debates. In Senegal, Guinea and Mali, progress was achieved when the non-governmental sector was able to come together in a structured platform to lobby constructively, creating essential pressure to make SSR a priority. The fact that civil society was able to play this role on security issues was new to each context. In Guinea, the consultation of civil society on security matters was unprecedented in the history of the country and played an important role in introducing new ideas and perspectives. In Mali, SSR was in part a response to popular criticism of the performance of the security services, with civil society framing the security debate for the first time from a human security perspective. In Senegal, Cissé argues that civil society pressure for improved security provision, in conjunction with wider agendas for political and economic change, represented a contributing factor to only the second democratic transition in the 54 years since Senegal's independence.

The potentially determinant role that civil society can play in promoting reform is demonstrated in their contribution to national dialogues in Mali, Liberia and Guinea. Through these national dialogue processes, civil society became a resource for the reform agenda. This included providing direct feedback on people's security needs; constituting a de facto accountability mechanism holding governments to deliver on reform promises they had openly and publicly committed to; and finally as a public relations measure, enhancing state legitimacy and trust through public consultation but also managing expectations by sharing information.

\section{Violence and conflict as reform 'triggers'}

Some of the narratives emphasise crucial reform moments as a result of the status quo being upended by incidents involving violent abuse or repression by the security services. In these examples, a strong public reaction catalysed the political agenda for reform. Such events constitute moments that can soften structural constraints on reform, making change not only possible but occasionally politically necessary. At such junctures, the availability, attitude and ability of specific actors can have a determinant effect on whether a moment of crisis translates into momentum for reform or only a brief rupture in the status quo. In Guinea, abuse by security services provoked public demand for change that contributed directly to making SSR a political priority during the 2010 transition. In Mali, the violent reaction of the security services to riots 
following a 2005 football match created public demand for improved security provision that was not satisfied by the replacement of senior security officials. In Senegal, incidents of repression by the security services during operations in the Casamance led to changes to the overall approach taken by the military in the region. While the primary objective of SSR should be understood from the perspective of preventing conflict, the opportunity offered by such catalytic moments to garner political will for reforms needs to be recognised. As discussed above, where civil society is well organised, a moment that galvanizes public demand for reform is more likely to become a platform for change.

Threats to state integrity and national security can also act as trigger events or catalytic moments. In the first instance, such threats can create barriers to reform. Armed challenges to state authority, originating either internally or from beyond national borders, provide increased political room for manoeuvre to argue that reforms re-orienting security management and oversight could compromise national security. Security threats can make it easier to co-opt reform agendas, including by exaggerating the risks and underselling the benefits of SSR. The scope for SSR in the context of threats to national security is therefore linked directly to the problem of reserved domains. At the same time, threats to national security may also sap public demand for reform by mobilizing fear of change at a moment when populations may feel vulnerable. The same dynamic can occur in the face of increased crime whereby a population may prefer a heavy-handed approach to policing even at the cost of political, civil and human rights because they perceive it to be countering a legitimate threat that requires a tough response. Yet at the same time, a threat to national security may lay bare deficiencies in national security and thus security sector governance and in this way can become a catalytic influence on reform. Considering Boko Haram in Nigeria sheds further light on these important dynamics because the threat to national security posed by this insurgent group was used by vested interests in the military to demand budget increases and to resist reform. However, as public frustration with the ineffective response to this threat grew, countering Boko Haram came to be seen as a major reason for the military to submit to reform with an increasingly vocal public constituency mobilizing on this issue. A similar dynamic is also illustrated in Mali as the state security forces struggled to respond to the threat from insurgents in the North of the country.

\section{Enabling governance-driven reform processes}

What do the micro-dynamics of security sector governance tell us about an enabling environment for reform processes? Drawing on the rich narratives of these six chapters, this section considers approaches that can contribute to effective, sustainable SSR and proposes 'signposts' for their implementation. 


\section{Fostering dialogue on security sector governance}

The roles, responsibilities and rights of different stakeholders are often unclear or disputed throughout the reform process, and as a result, every step is unnecessarily contentious. For security services reform may appear as a threat to their position, status and expertise, to say nothing of their livelihood or even their freedom where they face the prospect of transitional justice. The generalised lack of trust between different stakeholders in the contexts considered in this volume underlines the importance of building a shared understanding of what reform means, addressing the potential benefits and dangers it holds. This point is reinforced by the fact that failed attempts at SSR can be found in the history of every country covered in this volume: the experience of failure only increases the need for a shared vision of realistic and feasible change in the terms of security sector governance.

Histories of adversarial relations between the state, security services and citizens makes constructive engagement difficult and can lead to cycles of escalation. In each account, changes that occurred in the context of controlled democratic openings stalled when cardinal interests felt threatened, suggesting that security services and political elites did not share an understanding of their own interests in reform but saw change as a threat. Certainly moves towards more democratic security sector governance often require culture change within the security sector. Discussing new ideas in order to allay fears and build support is essential groundwork in order to carry a change process forward. Support to SSR should therefore focus on creating strategic opportunities for trust-building and engagement. Dialogue reduces the uncertainty associated with change and eases the way for reform-minded actors to seek out compromise solutions.

Engagement with civil society on security matters is an essential part of a meaningful dialogue around security sector governance. Indeed, the singular importance of civil society actors in promoting SSR and contributing to its momentum suggests the role of these actors in early stages of SSR is not sufficiently integrated into national political strategies or international support. However, this is not without risk, since civil society is not always or only a constructive partner in reform. From the perspective of security 'insiders', it is easy to characterise civil society advocacy as motivated by a desire to control or restrain security services, highlighting alleged abuses and seeking to limit their resources and operational remit. Certainly, in Nigeria the military rejected opportunities to engage with civil society both because this would result in 'humiliation' and because of a deeply rooted conviction that only the military is equipped to deal with military affairs. Again, from an 'insider' perspective, resistance is exacerbated by the apparently disproportionate significance of civil society 'outsiders' in promoting SSR.

These factors point to the need for bridge-building that can situate the respective roles of government and non-state actors, as well as intra-security 
sector relationships within a coherent approach to state and human security. This problem reflects the fact that attempted reforms did not take into account the rights of security personnel or emphasise the benefits that accrue to security institutions through improved effectiveness and accountability. Instead, SSR was perceived as placing new and sometimes controversial obligations on security services. Attempts to make these links in SSR initiatives were either incomplete or unsuccessful, suggesting a need for a deeper contextual understanding of inter- and intra-institutional dynamics.

Signposts for successful dialogue-driven interventions include:

- Security is 'demystified': there is increased public dialogue / debate on security, reducing fear and mistrust;

- A broad constituency of actors is engaged, creating bridges across different branches of government, the security sector as well as civil society and media;

- Discussion does not start with pre-conceptions about the objectives of reform but rather focuses on the vision and norms of the security sector, before addressing actual reform propositions;

- Communication is an integral part of the reform process: a public relations strategy should raise awareness and improve public understanding, while carefully managing expectations;

- Dialogue is not a one off but is sustained over an extended period, giving time for ideas to be shared and considered in depth, and for knowledge to spread.

\section{Creating a shared understanding of risks and benefits}

It is unrealistic to ask individuals to stake their personal future and well-being on a process that only vaguely defines what it aims to achieve and how. Strategic policies need to be translated into operational plans that lay bare the new direction of the security sector and allow each actor to understand their roles in concrete terms. This requires a long process of confidence-building based simply on talking through concepts and reform possibilities in pursuit of common understandings.

Supporting initiatives that emphasise the rights as well as the obligations of security services in an atmosphere of mutual respect is a first step towards correcting these tendencies, which have otherwise proved so damaging to reform efforts. Such approaches involve managing expectations. Emphasising the increased legitimacy for the security services which higher standards of professionalism and service delivery can generate, should be an integral element of SSR. At the same time, it is often the case that the public has unrealistic expectations both of SSR as a process, and the roles and responsibilities of security sector act- 
ors. Managing expectations and raising awareness about the respective roles, responsibilities and rights of actors on all sides will help to overcome and correct the imbalances that mistrust and unequal power relations breed.

Lack of resources is a common grievance within security institutions, leading to strong claims for force modernization, new equipment and improved conditions of service as evidenced in the accounts of security sector demands in Guinea, Mali, Nigeria and Senegal. Measures to support the effectiveness of security providers can incentivize wider reforms. Opportunities to contextualize improvements in effectiveness with improvements in accountability can be realised if the means and ends of modernisation are made the subject of public discussion. During the transition in Guinea, technical measures to improve conditions for the defence and security forces were an important first step in drawing them into a wider reform process. A similar dynamic unfolded in Nigeria, becoming a key link between reformist elements in the military leadership and the wider government. The subject of force modernization also offers the opportunity to initiate a public discussion on the vision for security and the means for achieving it. Consultative processes linked to national security policy development were effective at contextualising these types of discussions in Guinea, Liberia and Mali. Such dialogues can also be effective in ensuring that force modernization becomes part of a larger SSR process that tackles accountability as well as effectiveness: making this link is essential to ensuring that force modernization contributes to improved security sector governance.

One of the reasons that force modernization issues may stand at odds with better security sector governance is that security institutions often fail to recognise how SSR can serve their own interests. Fear of increased accountability and democratic civilian control can generate resistance and opposition within security institutions. This resistance may be based on an assessment of personal and corporatist interest, or instead reflect a truly different vision of the role of the security sector in a state. In either case, dialogue about the form, function and motivations for better security sector governance is essential to ensuring that security institutions become productive champions of the reform process instead of spoilers.

Signposts that can show the development of common understandings include:

- Inclusive national security policy processes create shared understandings of the roles and responsibilities of different security sector actors;

- Civil society engages with security services in a non-adversarial manner, creating a positive dynamic towards more openness and better service provision;

- SSR processes address the rights as well as the obligations of security sector personnel;

- Activities that address force modernization needs are linked to initiatives that reinforce oversight and accountability. 


\section{Binding constituencies into reform processes}

In each narrative the most promising moments for reform provided for more inclusive public dialogue processes, either as one-off initiatives (the Etats généraux de la Sécurité et de la Paix held in Mali in 2005); as part of a political process (the election of a new president in Senegal); or through transitional institutions (the engagement of the Conseil national de Transition on SSR in Guinea or the Governance Reform Commission in Liberia). Reform faltered when consensus around a shared vision broke down, or the path to reform was too vague to follow with adequate accountability.

Broadening the shared vision of what reform is and what it should achieve is helpful even if discussions include only elite actors as a first step-for example, parliamentarians, executive staff and security services. Reforms will be better sustained if entry points can go beyond the usual SSR constituencies: extending from core security oversight bodies, to include other actors such as state finance authorities and independent oversight institutions with broad responsibilities in anticorruption or defence of human rights, for example. The engagement of human rights advocates has often been catalytic at different junctures of the process.

The importance of civil society as a potential change agent is magnified by the relative weakness of other institutionalized systems of oversight (especially the parliament and the judiciary). Because these formal institutions are often under-capacitated and dominated by executive influence, the informal and public oversight that civil society can offer becomes disproportionately important compared to their formal role. In an example that is both significant and rare, Aiyede describes how a human rights lawyer, Festus Keyamo, obtained a high court judgement challenging the unconstitutional practice of the President appointing service chiefs without the approval of the National Assembly. This led to the President referring the 2014 appointments back to the Senate, showing how formal and informal oversight functions can be mutually reinforcing. Tensions between this process of formalisation and the continued existence of reserved domains can also be seen in the horse trading around the 2008 National Defence Act in Liberia, or in the stalling of defence reform in Mali. The contested nature of these processes illustrates that a constitutional or legal basis provides an important reference point for security sector roles and responsibilities.

The different ways that political will can be withdrawn points to the need for clear and public reform plans against which executive authorities can be held publicly accountable for lack of progress. In the best-case scenario, this shared vision of security sector governance should be articulated in a public statement of reform goals, and if possible, steps to be taken over a specified time-frame. Creating and sharing such a joint vision of change may also prevent reversals and backsliding, by providing a clear benchmark against which progress - and thelack of it - can be clearly measured. 
Signposts that show constituencies being bound into reform processes include:

- Conversations around security sector governance extend beyond the usual suspects, who may be seen as opponents or allies of the status quo, to include different political parties, unions, and professional organisations, including private and commercial security interests; this also makes room for input from marginalised constituencies, such as youth, women's groups, and the poor;

- Structured groupings of civil society actors, such as working groups or national coalitions, allow civil society from diverse interests and backgrounds to speak with a unified voice, gaining influence through speaking from a legitimate platform;

- Parliament visibly assumes its prerogatives in the area of security sector oversight;

- A national dialogue on SSR is grounded through being directly linked to the revision or development of security policy and legislation.

\section{Calibrating international SSR support}

As discussed in the introductory chapter to this volume, the SSR approach has been frequently accompanied by large claims and unrealistic expectations. In contexts where state capacity has failed to address a resurgence of internal and cross-border conflicts, there is an increasing tendency to prescribe SSR as a stabilization tool. The narratives explored in this volume should caution against such overloading of the SSR agenda. The trust that is required in order to coax security actors to commit to reform is difficult to achieve even in stable political environments, let alone during conflict. The factors that lead to destabilisation and conflict are central to the dynamics that SSR aspires to transform, including the nature of public service provision and the legitimacy of state authority. This underlines the essentially prevention oriented nature of SSR. Ensuring that the security sector is both effective and accountable within a framework of democratic governance, rule of law and respect for human rights, provides a legitimate basis for SSR that unites both national stakeholders and international partners.

This section draws from the narratives of security sector governance set out in this volume to consider implications for international SSR support. It focuses on two key dimensions: donor approaches from a process perspective and under-emphasised vectors of SSR engagement.

\section{Re-orienting donor approaches}

A shared understanding of SSR and its potential benefits needs to be established in order to build support for reforms among constituencies that might 
otherwise perceive such a process as threatening. However, supporting governance-focussed SSR that can help create this kind of consensus poses a challenge for current international approaches to SSR. In the absence of actual reform activities, a defined reform agenda is frequently seen as a required sign of political commitment and good intentions. Putting aside time to talk does not offer tangible results against which donors can measure their own effectiveness and is therefore systematically undervalued. The value of confidence-building through dialogue is underrated. Simply talking about reform, without making any concrete plans, can also be seen as a way for reform spoilers to hijack reform programmes and divert reform away from a more transformative agenda. While there is some danger of this, it is also clear that discussion is the only means by which a broad-based and shared vision of change can be constructed and that without this the risk of failure increases dramatically. It is well known that SSR is controversial because it seeks to change the dynamics of power relations in the security sector. In short, it risks creating winners and losers. Translating this tension into an operational policy response means seeking out opportunities to build trust among stakeholders and foster a shared vision.

It is inherently difficult for international partners to avoid doing more harm than good when contributing to sensitive national discussions. The programme delivery mechanisms used by donors will influence the likelihood of success. Thus, sensitivity within the Nigerian military over assistance in the area of civil military relations is not only a result of the message but also the (US) messenger. Similarly, the outsourcing of the military reform process in Liberia to a private military and security company created significant problems in terms of the credibility of nascent Liberian governance institutions. In this respect, South-South cooperation in promoting reform offers a much more promising route since states that have already traversed the challenges of the reform process have both pragmatic expertise to offer and a moral authority from which to speak.

Donors often apply great pressure to make visible and early progress. A tendency exists to confuse the value of an SSR programme with its cost, meaning that more is expected of expensive SSR interventions than of comparatively less costly governance-focussed activities. This diverts focus away from identifying progress in governance, while directing more attention and much greater resources to infrastructure, training and equipment activities that privilege effectiveness over security sector governance. Based on the perspectives presented in this volume, a focus on the 'technical' elements of reform appears especially wrong-headed. The nature and scale of structural change implied in transformational SSR means that reforms focused on force capacity and equipment - often the most visible signs of change - are unlikely in isolation to herald significant shifts in the structural conditions of security governance within a state.

While the claim that "SSR is about politics" is a common-place statement in SSR policy discussions, the norms and values governing who has a say in secur- 
ity provision, management and oversight remain under-analysed. One aspect of this problem is the automatic linkage of buy-in from political elites to donor funding decisions. To cite just one example, in Mali, UN funding for PGPSP was cut when executive support waned. This was arguably the time when efforts should have been increased. Because power moves through deeper social structures, the reasons why formal roles and responsibilities are unheeded remain unrecognised (van Veen and Price, 2014, Hills, 2014, Schroeder and Chappuis, 2014). The emphasis on visible, tangible, outward signs of change (things that can be counted, measured, bought and paid for) exacerbates this tendency to overlook shifts in expectations, attitudes and values surrounding security provision, management and oversight. Yet these intangibles are essential elements without which there will be no change in the way that force is used and controlled by state and non-state actors.

If the preference for technical over governance-focused reform reflects the fact that what we consider success in SSR is often measured by the wrong metric, then a further example of this approach is the continuing tendency to focus on top-down aspects of institutional reform instead of starting from bottom-up experiences of security. While a nuanced understanding of elite politics is important to revealing the conduits of power within a state, the ultimate measure of success in SSR should be the subjective experience of security at the level of the population. Methodologies have not yet adequately integrated the fact that security is a subjective, inter-personal experience that interacts with political judgments about legitimacy and power as well as institutional configurations of coercive force.

Overcoming these problems requires innovative approaches that can offer new interpretations of progress and impact. Longer term engagement is needed based on a flexible SSR methodology. In terms of measurement and evaluation, much conceptual and methodological work remains to be done to develop tools that aptly capture the real value of governance-driven reform agendas. Cutting-edge qualitative methods could be applied with greater effectiveness in fragile contexts to capture changes in the indicators that actually matter such as organisational culture, modes of service delivery and public legitimacy.

\section{Valorising 'Soft' SSR}

The importance of a shared vision of security among reform constituents suggests that apparently 'soft' measures that focus on discussion, transparency and consultation may be crucial in creating openings for SSR. Creating the trust that is necessary to carry the reform process forward will require raising awareness of reform concepts, building networks among reform constituencies, and sensitizing actors on all sides to different perspectives and security needs.

Support for improved security sector oversight remains under-emphasised and under-resourced. Parliamentary capacity development remains a priority 
area of SSR activity that could benefit from a stronger institutional focus: in concrete terms this suggests focussing on parliamentary support, including staff development and committee functions, as well as individual representatives and engagement with civil society and the media. Training for media and government staff on security issues is essential. This could mean involving media in the process of discussion as well as providing training on responsible reporting for government and media.

The reform processes considered in this volume often failed to translate rhetorical commitments to SSR into concrete improvements in institutional governance arrangements or improvements in security service provision. While on the surface this may look like a case of too much talk and not enough action, in fact the reverse is true. Reform faltered at junctures where key constituencies within the security sector felt their interests were threatened. The sense of threat was in part based on flawed understandings of how SSR could affect their interests. A shared vision of how the security services stand to benefit from improved accountability and professionalism needs to be established early on in order to defuse a confrontation of interests before it arises.

Creating a shared vision for security sector governance needs to be based on a nuanced understanding of security threats and reform priorities. As evident across the national narratives, state-centric approaches are out of touch with the reality of security provision since the state is not the only, nor in many cases the most important security provider, nor is it the most trusted. A realistic assessment of reform needs is impossible without an understanding of how non-state security providers are meeting generalised needs for security in the absence of a people-centred state security sector.

At least two different facets to the privatisation of security are directly relevant to SSR: on the one hand, community-based non-state security and justice providers organise themselves in various ways to meet the self-protection needs of the communities they stem from; while on the other hand, commercial security providers, of both national and international origin, supply security on a market basis to those with the means to pay for it. These two groups represent different facets of the privatisation phenomenon but both are essential in understanding how to reform the security sector because they exist at least in part as a result of the state's failure to provide sufficient security for the population. Their activities in turn have a direct effect on the nature of public security provision and the relative legitimacy of the state as security provider. No SSR programme can realistically aspire to improve human security without accounting for both types of non-state security actor.

\section{Conclusion}

SSR is no longer a new agenda; it is necessary to reflect on shortcomings and to identify innovations in the approach and its application. While the results 
of reform efforts may be judged underwhelming, the fault may lie less with the results themselves than the analytical tools at our disposal for understanding and interpreting them. While no one would claim that West Africa's nations no longer suffer the dysfunctions that first made SSR relevant to the region, it would also be a mistake to claim that no progress has been made. Instead an analysis based on a revaluation of what matters in SSR and what it looks like in practice, yields a distinctly more nuanced picture. This collection of local narratives has sought to provide such a perspective through the lens of six unique moments in long and uncertain trajectories of change.

The time is right to critically evaluate current approaches to SSR in order to maximize its contribution to wider security, development and democracy promotion discourses. Indeed, good governance of all aspects of public service delivery is a cross-cutting theme of the post-2015 agenda for development. Through emphasising the need to build peaceful inclusive societies based on access to justice and effective, accountable institutions, the framework of the Sustainable Development Goals offers an important opportunity to promote a holistic SSR approach. Although the goals are universal, the pathways to achieving them are not: success will be defined by whether we are able to understand the specific realities of distinct reform contexts. It will depend on collectively maintaining a commitment to good governance, human rights and democracy.

As this volume has sought to demonstrate, unpacking the micro-dynamics of security sector governance is essential if national actors and international partners are to develop partnerships that are context-sensitive, based on trust and respectful of local ownership. These realities need to be recognized in order to seize reform opportunities and understand constraints. Despite the challenges described throughout this volume, the overall message emerging from these narratives is by no means negative. If it is clear that the political space for reform is limited, under-exploited channels do exist to create such space. We hope that these narratives of security sector governance in West Africa provide a basis to reflect, learn and seize such opportunities.

\section{Notes}

${ }^{1}$ For more on these distinctions, see Bagayoko (2010: 279-298). 